\title{
Linx
}

Revue des linguistes de l'université Paris X Nanterre

$42 \mid 2000$

Approches sociolinguistiques du plan phonique

\section{Franck NEVEU (ed.), Faits de langue et sens des textes}

Au titre du droit de réponse

\section{Frank Neveu}

\section{CpenEdition}

\section{Journals}

Édition électronique

URL : http://journals.openedition.org/linx/992

DOI : $10.4000 / \operatorname{lin} x .992$

ISSN : 2118-9692

Éditeur

Presses universitaires de Paris Nanterre

\section{Édition imprimée}

Date de publication : 1 juin 2000

Pagination : 181

ISSN : 0246-8743

Référence électronique

Frank Neveu, « Franck NEVEU (ed.), Faits de langue et sens des textes», Linx [En ligne], 42 | 2000, mis en ligne le 05 juillet 2012, consulté le 22 septembre 2020. URL : http://journals.openedition.org/linx/992 ; DOI : https://doi.org/10.4000/linx.992

Ce document a été généré automatiquement le 22 septembre 2020

Département de Sciences du langage, Université Paris Ouest 


\section{Franck NEVEU (ed.), Faits de langue et sens des textes}

Au titre du droit de réponse

Frank Neveu

\section{RÉFÉRENCE}

Franck NEVEU (ed.), Faits de langue et sens des textes. Paris, SEDES, 1998, 302 p.

\section{NOTE DE L'ÉDITEUR}

Prenant acte du dysfonctionnement qui a marqué la publication du compte-rendu de l'ouvrage collectif édité par Frank Neveu Faits de langue et sens des textes (Sédès, 1998), le Comité de Rédaction publie la réponse demandée par le responsable de l'ouvrage.

1 La revue Linx a publié dans son numéro 41 (pp. 168-170) un compte rendu d'un ouvrage collectif dont j'ai assuré la direction, Faits de langue et sens des textes, et qui rassemble les communications proposées à un colloque d'agrégation qui s'est tenu à l'Université Paris VII en novembre 1998.

Le texte de ce compte rendu, attribué à "Jean Wirtz», plaisamment rattaché à l'Université de Berne («ville» et «duperie »), est très précisément identique à celui proposé à L'Information grammaticale en décembre 1998 par J.-F. Jeandillou (Université Paris $\mathrm{X}$ ), et refusé par le comité de rédaction de la revue en raison de son caractère hâtif et ouvertement malveillant (procédant par insinuations, l'auteur y énonce un jugement négatif a priori sur l'entreprise de ce colloque et de sa publication, au lieu de proposer, comme il se doit, un examen minimalement argumenté des contributions).

3 Dans son acrimonie, l'auteur de ce texte a omis, semble-t-il, de prendre suffisamment en compte l'existence au premier degré de l'Université de Beme, et celle d'un lectorat, 
qui, soucieux de s'informer de l'actualité linguistique, n'est pas nécessairement préparé à trouver dans ces pages de la prose de folliculaire, ni donc à lui ménager le traitement interprétatif qui lui revient. Et ce qui pourrait apparocitre de prime abord comme le canular pathétique d'un spécialiste de la supercherie manifeste en réalité un manquement certain à la déontologie universitaire. D'une part, parce que l'auteur révèle bel et bien derrière cet usage de la pseudonymie son incapacité à assumer publiquement la responsabilité de son propos, avouant du même coup la vraie nature de son entreprise. D'autre part, parce qu'il s'autorise, avec le plus souverain mépris, à compromettre une université étrangère dans ce jeu de cache-cache dérisoire. Enfin, parce qu'il contribue à jeter le discrédit sur une revue qui a fait depuis longtemps les preuves de son honorabilité scientifique.

4 Un tel souci de l'institution universitaire et de ceux qui la font vivre force l'admiration. Il n'y manquait plus que le style. Mais n'est pas Prévost-Paradol qui veut. Souhaitons à l'auteur de ce texte plus d'inspiration, une autre fois, et surtout dans un autre cadre.

\section{AUTEURS}

\section{FRANK NEVEU}

Université Paris VII

Université de Berne 